\title{
Appraisal of Fire Safety Management Systems at Educational Buildings
}

\author{
N. Nadzim ${ }^{1}$, M.Taib ${ }^{2, a}$ \\ ${ }^{1,2}$ School of Housing, Building and Planning, Universiti Sains Malaysia, 11800, Penang, Malaysia
}

\begin{abstract}
Educational buildings are one type of government asset that should be protected, and they play an important role as temporary communal meeting places for children, teachers and communities. In terms of management, schools need to emphasize fire safety for their buildings. It is well known that fires are not only a threat to the building's occupants, but also to the property and the school environment. A study on fire safety management has been carried out on schools that have recently experienced fires in Penang. From the study, it was found that the school buildings require further enhancement in terms of both active and passive fire protection systems. For instance, adequate fire extinguishers should be provided to the school and the management should inspect and maintain fire protection devices regularly. The most effective methods to increase the level of awareness on fire safety are by organizing related programs on the management of fire safety involving all staff, teachers and students, educational talks on the dangers of fire and important actions to take in the event of an emergency, and, lastly, to appoint particular staff to join the management safety team in schools.
\end{abstract}

\section{Introduction}

School buildings are structures where the implementation of fire safety is of utmost importance. The majority of the occupants in schools consist of children and youths who easily panic and become difficult to manage in the event of an emergency or crisis. Proper management could help deal with this situation to prevent further accidents from happening. Damages may be devastating when a school catches a fire. Such damages constitute loss of life, property and operation of schools [1]. Major fires have revealed that a safe escape from a burning structure is not always possible for everyone [2]. Therefore, installing fire protection systems, such as portable fire extinguishers as measures to prevent fires, is essential to slow down the spread of flames to other places. A skilled person who knows how to use fire extinguishers can help to extinguish a small fire before it becomes large. In the prevention of fire, there are particular areas that need to be checked as well as procedures that need to be taken during an emergency such as identifying where fire may break out, high risk areas and possible consequences of fire. It is important to know that fire safety is not just dynamics involving smoke control, sprinkler systems, detection, fire departments, structural endurance and fire prevention or risk management.

${ }^{\mathrm{a}}$ Corresponding author : mariati@usm.my 
Fire safety measures also take into consideration risk areas such as store rooms and science laboratories that must be monitored frequently by the management. All materials must be kept tidy and arranged properly. In addition, the relationship between human behaviour and response when fire occurs is a particularly difficult issue [4]. Lack of situation awareness results from poor gathering, filtering and understanding of time dependent information, which may complicate emergency situations and lead to secondary casualties and property losses [5].

\section{Definition of Fire Safety Management}

The word management can be simply defined as the combination or co-ordination of some activities or programs consisting of a manager and a team to achieve the goals. In terms of fire safety, management is the combination or co-ordination of some activities or programs towards the prevention of damage from fire. Such programs include fire drill training, staff training, fire prevention (housekeeping, periodic inspections, etc.), escape routes and others.

A fire safety management program should be divided into 8 elements, which are inspections, education and training, fire suppression, emergency service, evaluation of fire possibility, fire prevention, reports, as well as record keeping and communication [6]. Failure to do so means that one or more strategies may fail and, because one strategy may be dependent on another, more strategies may fail, resulting in increased risk.

\section{Site Selection}

Two educational buildings were selected as case study buildings on Penang Island. The selected buildings were Sekolah Jenis Kebangsaan (Cina) Min Sin and Sekolah Menengah Kebangsaan Abdullah Munshi. The reason of choosing these schools was because they had both experienced fires last year, in 2013. The fires destroyed a few parts of the buildings, however, no injuries were sustained. Sekolah Jenis Kebangsaan (Cina) Min Sin is located at 86, Jalan Tun Dr. Awang, Relau, 11900 Bayan Lepas, Pulau Pinang. The building was built in 2004 and consists of three blocks which are Block A, Block B and Block C. A guard house was fully burnt and the cause of fire was due to a short circuit. Sekolah Menengah Kebangsaan Abdullah Munshi is located at Jalan P.Ramlee, 10460 George Town, Pulau Pinang. The building is comprised of six blocks within the school premises. The fire incident happened in a corridor near the entrance to the school canteen. The cause of fire was also from a short circuit caused by old wires. It was important to conduct site visits to both of these schools in order to identify the current condition of the buildings in terms of fire safety management systems applied there.

\section{Results and Discussion}

\subsection{Management Duties}

Both schools have appointed members of staff to be part of a fire safety management team with different positions and roles. There were several other roles established such as emergency services command, administrative services command, volunteer services command and support services command. All of these roles were entrusted to the person in charge and they were expected do their work according to the requirements and roles in management. The management is supervised under the Senior Assistant of Student Affairs with help from other members. The management have meetings twice a year to present the overall conditions and improvements that had been done towards fire safety. 


\subsection{Housekeeping}

Both schools have their own housekeeping services. Housekeeping services are responsible for cleaning up rubbish and dusting, disposal of rubbish, cleaning up after workers and keeping travel areas tidy, well-lit, and ventilated. From observations at SMK Abdullah Munshi, the school failed to keep a few areas in the school building tidy, especially along the escape route. Figure 1 shows unused furnishing materials left unattended outside a classroom. They were left along the corridor and affected the overall width of the walkway. Figure 2 shows other wooden materials placed at the centre of the walkway to a classroom and the canteen. The materials were quite big in size and obstructed the walkway passage from being clear.

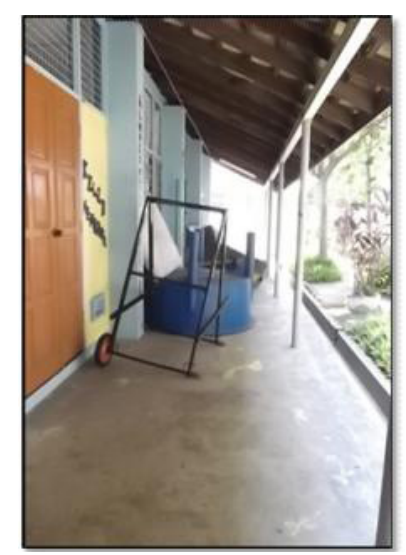

Fig.1: Unused and broken materials are left along the corridor outside the classroom

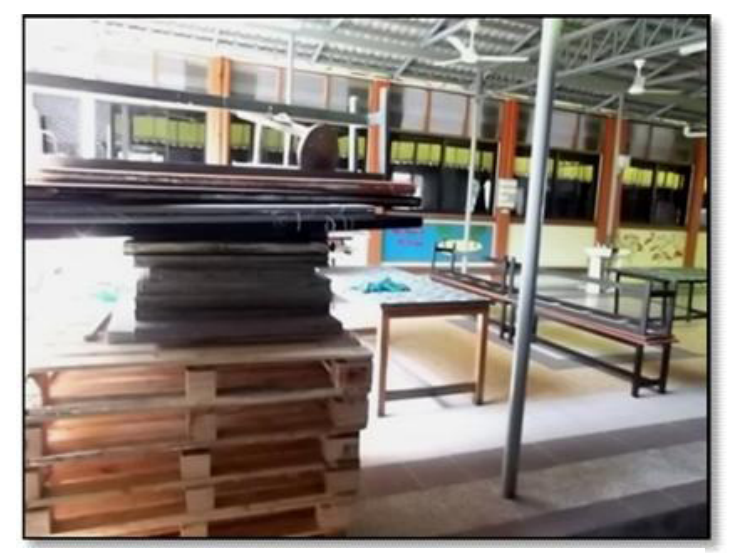

Fig.2: Flammable materials are placed at the centre of the passage

At SJK (C) Min Sin, the housekeeping service was good overall. Its condition was tidy and free of rubbish. Observations were made not just outside the classroom, but also inside the classrooms. The furniture was arranged properly and was tidy.

\subsection{Fire Drill Training}

SJK (C) Min Sin conducts fire drills four times in a semester, while SMK Abdullah Munshi conducts them twice a year. The drills involve all of the staff and students. The students are trained to use the escape route provided and not to panic. When the alarm sounds, teachers act as guides to lead the students on every floors to move out from the building within the prescribed time, which is less than 3 minutes. This prescribed time is used for both schools to ensure all the occupants in the building securely escape to a safe place and are not trapped in the fire.

\subsection{Alarm System}

When emergencies happen, someone gives a warning to the other occupants in the building using a manual break glass call point. Once triggered, the alarm will continue to sound out automatically. Fire alarms had been installed on every floor for both of the school buildings. Figure 3 shows the fire alarm installed on every floor of SJK (C) Min Sin. When someone breaks the glass, the action will then connect the alarm panel board. Then, from the board, the sound will release. The indication zone with red light in the panel board shows which parts of the building are experiencing a problem or emergency. The system is located on exit routes, close to the hose reel. As such, nobody in the building needs to travel more than 30 metres to access it. The system is mounted at a height of $1.4 \mathrm{~m}$ from the floor, easily accessible and well illuminated. 


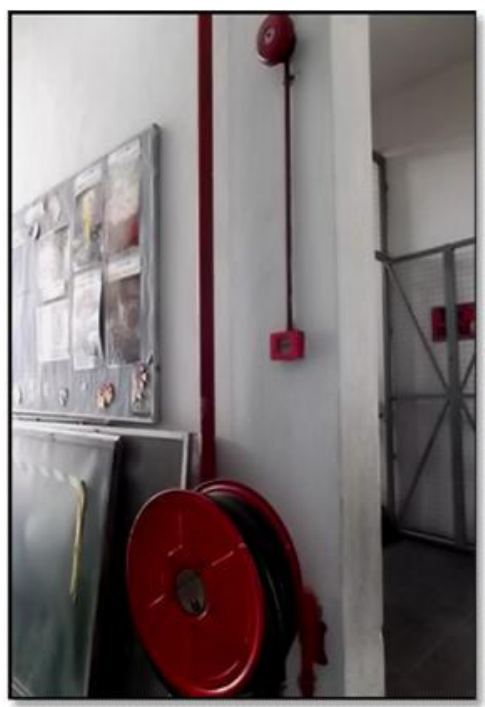

Fig.3: Break glass installed on every floor of the building with a hose reel

\subsection{Escape Routes}

UBBL (by-law 166) states that not less than two separate exits shall be provided from each storey together with additional exits as may be necessary [8]. The number of exits required for a given building or assembly place is dependent on the maximum number of people that can occupy a space, the capacity of each exit and the travel distance required. Based on observations, the school buildings have both complied with these requirements.

In addition, the escape routes must be clearly marked and all fire exit signs should be located in places that clearly indicate escape routes. Corridors and stairways that form part of escape routes should be kept clear and hazard-free at all times. Items that may be a source of fuel or pose an ignition risk should never be located on any corridor or stairway that will be used as an escape route.

Both schools had already implemented fire escape signs to inform the occupants which routes they should take to escape from fire. Figure 4 shows the escape signs in SJK (C) Min Sin which are attached to the wall near the staircase. In SMK Abdullah Munshi, red arrows were used to indicate the escape routes. The occupants will refer to the arrows which indicate the direction to a safe place (place of assembly). Figure 4 shows the escape signs that are used in SJK (C) Min Sin. They are located at every floor and the signs are clearly visible for everyone to see.

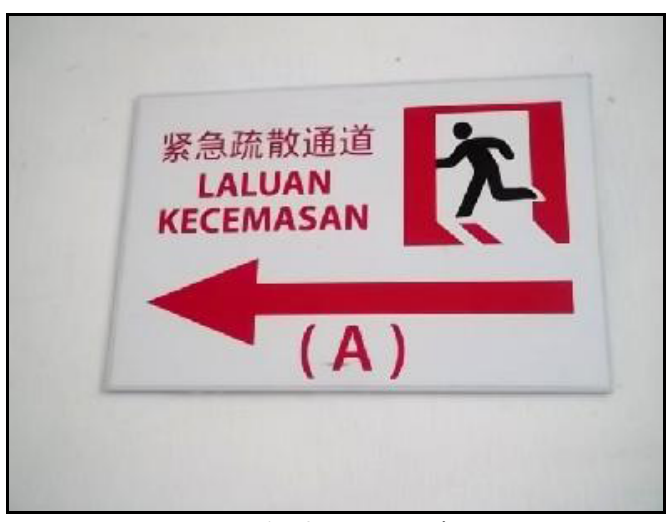

Fig.4: Escape sign 


\subsection{Place of Assembly}

The condition of the place of assembly is in good. Figure 5 shows that the school field at SMK Abdullah Munshi, which is used as the place of assembly, is properly maintained in that the grass is cut short and there are no obstructions or rubbish. Figure 6 shows a place of assembly for SJK (C) Min Sin. The place of assembly is chosen by the fire brigade with consideration for the requirements stated in the laws and regulations. There are three places of assembly for this school. Place A and Place B are located in front of the building, while Place C is located at a small field behind the school building. During a fire, the occupants will move to the nearest place of assembly which can accommodate the total number of occupants in the building.

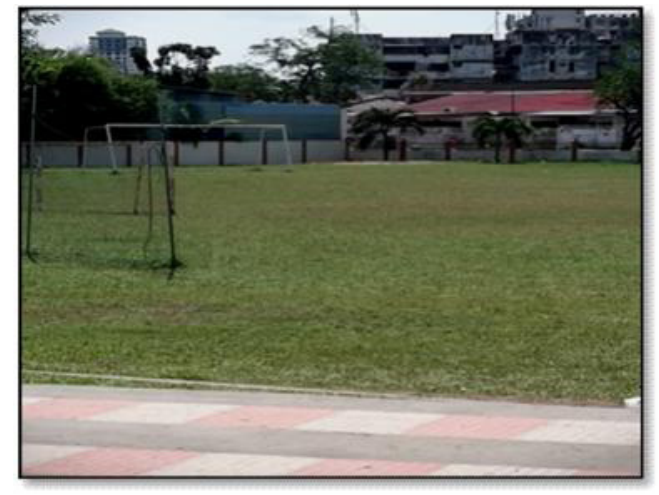

Fig. 5: School field as a place of assembly at SMK Abdullah Munshi

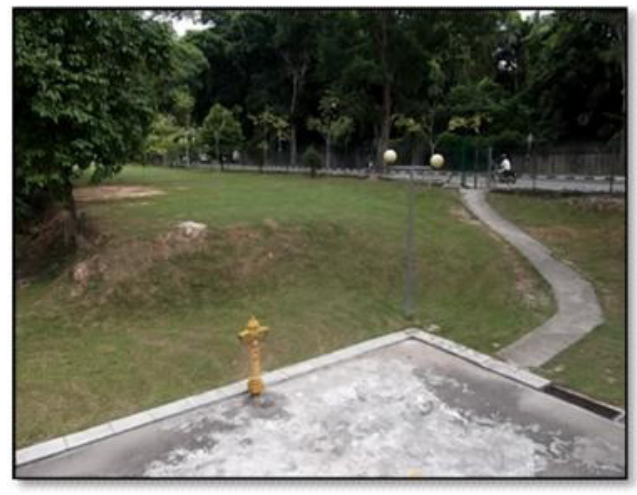

Fig. 6: Place $\mathrm{C}$ as a place of assembly for SJK (C) Min Sin

\subsection{Staircases}

The school buildings have at least two staircases in every block. The size of the staircases, the length and width all follow the requirements in the UBBL. The width of the staircases is maintained throughout the entirety of its length, including the platform. By-law 168 stipulates that every upper floor shall have at least two separate exit staircases and the distance in between two exit staircases shall not be less than 5 metres. Figure 6 shows that the staircases in both schools are in good condition.

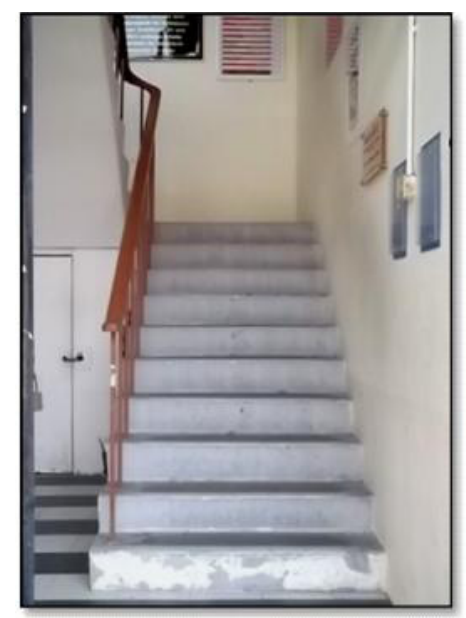

Fig. 7: The staircases are in good condition with no obstructions preventing the passage 


\subsection{Checking and Updating Portable Fire Extinguishers}

The management has made an inspection schedule to check and update expired fire safety equipment, particularly the fire extinguishers. SJK (C) Min Sin regularly maintains the fire extinguishers twice in a year, while SMK Abdullah Munshi updates their fire extinguishers once a year. It was observed that a few fire extinguishers were not maintained and had been left unattended for a few years. Figure 8 shows the poor condition of the fire extinguisher. The hose is also not in its proper place. These conditions show that there is a lack of maintenance and awareness from the management on the importance of fire safety equipment installations in the building.

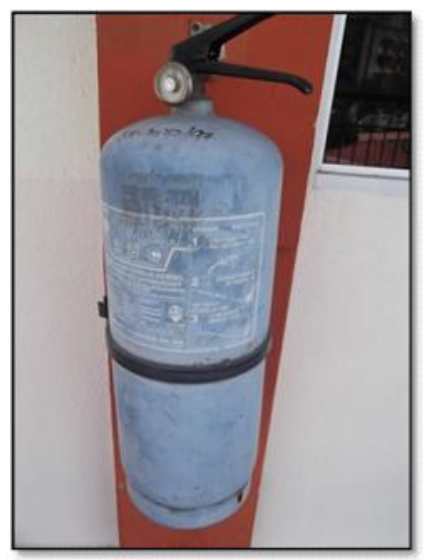

Fig. 8: The expired portable fire extinguisher is still in use for one part of the building

\subsection{Old Wires and Improper Wire Arrangements}

Lack of maintenance and inspection of electrical wires has left some wires sticking out and unattended. Fires caused by faulty or malfunctioning wiring could be easily spread or quickly get out of control. Figure 9 shows the electrical wires for an air-conditioner which are scattered and exposed on the outside of the building. Figure 10 shows the old wires that caused the original fire, charring from which can be seen on the wall. Before the fire incident, the school cut the old wires without knowing that they were still active and exposed to the weather. Exposure to rain water caused circuits to short, which eventually led to a fire.

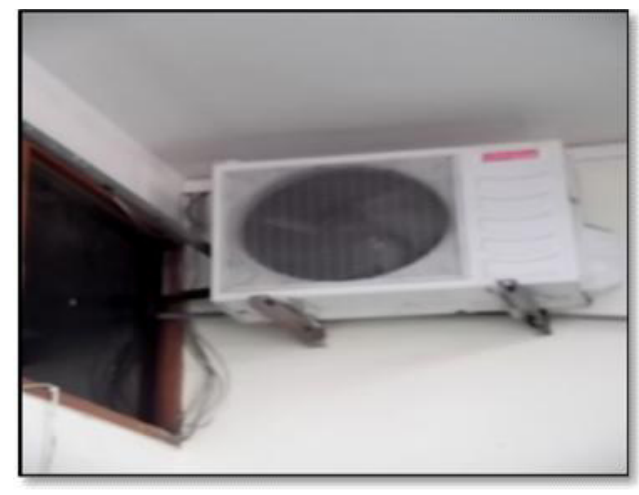

Fig. 9: Scattered wires are left unattended

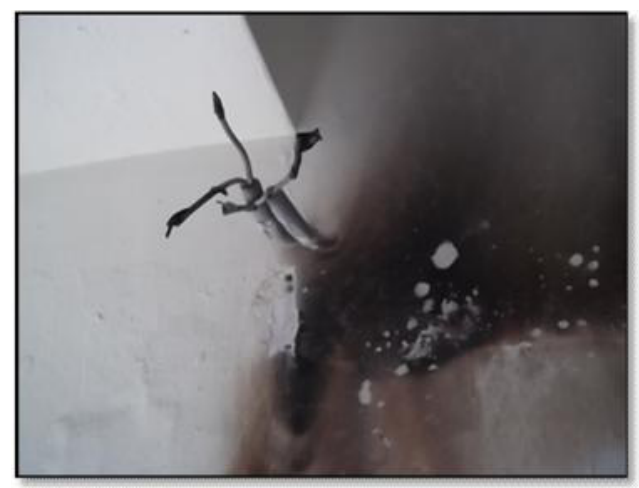

Fig. 10: Old wires that cause short circuits and fire 


\subsection{Assisting the Fire Brigade}

All of the fire safety equipment and fire brigade access must be clear from any rubbish or obstructions that may cause difficulties for the fire brigade to extinguish the fire. From observations at both schools, there were no obstructions or vehicles placed near the hydrant. However, it was noted that there was equipment that had been broken for a long time and no further action had been taken to repair it.

\section{Conclusion}

In order to provide total safety for buildings, fire safety management must be properly implemented by a full commitment, either from local government authorities, educational building authorities or the users and occupants of the building. All of them play important roles in achieving the goals of fire safety management. Based on the findings and analysis, it can be concluded that most of the fire safety and prevention requirements stated in the UBBL have been applied to the two case study school buildings. However, there are a few recommendations and improvements which need to be followed for fire safety management in all educational buildings. Broken equipment should be replaced or maintained properly so that it functions well. Sometimes, lack of inspection and awareness of trivial issues bring about a big negative impact in the future. The management should appoint specialists in a particular field to do work that involves his or her expertise, such as in electrical installation. In brief, although the implementation of fire safety management is quite costly nowadays, proper attitudes or actions taken by building owners, staff and management teams in handling fire safety management in the building are needed in order to uphold successful fire safety measures.

\section{References}

1. A.Hassanain M. (2006). Towards the design and operation of fire safe school facilities. Fire safe school facilities, 15, 838-846.

2. M. Kobes, I. Helsloot, B. deVries, J. G. Post (2010). Building safety and human behaviour in fire: a literature review. Fire Safety Journal, 45, 1-11.

3. Fitzgerald, R.W. (2004). Building Fire Performance Analysis, ISBN: 0-470-86326-9, Pp. 79.

4. Meacham, B. J. (1999). Integrating human behaviour and response issues into fire safety management of facilities. Facilities, 7, pp.303-312.

5. N. Groner, C. Jennings, A. Robinson (2012). A Negotiated-Text Method for Assessing Situation Awareness Information Requirements from Emergency Responders, IEEE Computer Society, New Orleans, LA, United states, 259-263.

6. Chow W.K. (2001). Review on fire safety management and application to Hong Kong. International Journal on Engineering-Based Fire Codes, 3, 52-58.

7. Tsui, S. C. and Chow W. K. (2004). Legislation aspects of fire safety management in Hong Kong. Facilities. 149-164.

8. Undang-undang Kecil Bangunan Seragam 1984 [p.w. 5178/85], ISBN: 967-89-1570-7 